Kansas State University Libraries

New Prairie Press

\title{
MODELING THE BODY TEMPERATURE OF HEAT STRESSED HOLSTEIN LYING COWS UNDER TWO DIFFERENT COOLING PROCESSES
}

M. Zhou
A. M. Parkhurst
P. E. Hillman
C. N. Lee

See next page for additional authors

Follow this and additional works at: https://newprairiepress.org/agstatconference

Part of the Agriculture Commons, and the Applied Statistics Commons

\section{(c) (1) $\Theta \Theta$}

This work is licensed under a Creative Commons Attribution-Noncommercial-No Derivative Works 4.0 License.

\section{Recommended Citation}

Zhou, M.; Parkhurst, A. M.; Hillman, P. E.; and Lee, C. N. (2005). "MODELING THE BODY TEMPERATURE OF HEAT STRESSED HOLSTEIN LYING COWS UNDER TWO DIFFERENT COOLING PROCESSES," Conference on Applied Statistics in Agriculture. https://doi.org/10.4148/2475-7772.1136

This is brought to you for free and open access by the Conferences at New Prairie Press. It has been accepted for inclusion in Conference on Applied Statistics in Agriculture by an authorized administrator of New Prairie Press. For more information, please contact cads@k-state.edu. 
Author Information

M. Zhou, A. M. Parkhurst, P. E. Hillman, and C. N. Lee

This is available at New Prairie Press: https://newprairiepress.org/agstatconference/2005/proceedings/6 


\title{
MODELING THE BODY TEMPERATURE OF HEAT STRESSED HOLSTEIN LYING COWS UNDER TWO DIFFERENT COOLING PROCESSES
}

\author{
M. Zhou ${ }^{1}$, A. M. Parkhurst ${ }^{1}$, P. E. Hillman ${ }^{2}$, and C. N. Lee ${ }^{3}$
}

1. Department of Statistics, University of Nebraska at Lincoln

2. Biological and Environmental Engineering Department, Cornell University

3. Department of Human Nutrition, Food and Animal Sciences, University of HawaiiManoa

\begin{abstract}
Heat stressed cows produce less milk. Thus, a major challenge during hot summer months is to keep the dairy barn at a comfortable temperature. Use of fans is an economical solution but the combination of both spray and fans appears to be an even more effective way to cool cows and improve the milk production than using fans alone. The goal of this study is to recommend an appropriate method for comparing the dynamics of the cooling processes. The first step is to develop a nonlinear model to characterize the thermoregulatory responses of heat stressed dairy cows when they are lying down. The next step is to evaluate methods of comparing treatment effects such as mixed model analysis of the parameter estimates, nonlinear fixed effects analysis, and nonlinear mixed effects analysis. The final step is to illustrate the recommended analysis.
\end{abstract}

\section{INTRODUCTION}

Keeping cows calm and tranquil remains a major challenge to farmers during hot summer months since heat stressed cows produce less milk. Cows can be heat stressed at a Temperature Humidity Index (THI) of only 72 (Armstrong 1994). Keeping a dairy barn below a THI of 72 can be accomplished by air conditioning; unfortunately, it is very expensive (Bray et al. 2003). Use of fans is an economical solution (Spain and Spiers 1998, Hillman et al. 2001, Frazzi et al. 2000, and Brouk et al. 2003) but the combination of both spray and fans is an even more effective way to cool cows (Hillman et al. 2001, Frazzi et al. 2000, and Brouk et al. 2003) and improve milk production (Igono et al. 1987, Strickland et al. 1989, Bucklin et al. 1991, Lin et al. 1998, Meyer et al. 2002, Turner et al. 1992) Although it is known that spray and fans effectively cool cows, we know of only one study that tracks the effectiveness of spray and fans on the thermoregulatory responses of unrestrained cows in a freestall facility (Hillman et al. 2005). We propose expanding the characterization of those thermoregulatory responses.

It is common for cows to spend between 11 to 12 hours a day lying in freestalls (Friend and Polan 1974, Perera et al. 1986); however, when heat stressed, they spend less time lying and more time standing (Hayasaka 1990, Frazzi et al. 2000, Overton et al. 2002, Perera et al. 1986, Shultz 1984). Standing has the thermal heat loss advantage over lying because more surface area is available for evaporation. We assume each lying down episode (a lying event) becomes an indication of discomfort (heat gain). As the body 
temperature rises, the cow becomes thermally challenged and needs to stand in order to cool.

The objectives of this study are: to develop a nonlinear model to characterize the thermoregulatory responses of lying heat stressed Holstein dairy cows; to evaluate three methods of comparing the two cooling strategies: mixed model analysis of the parameters, nonlinear fixed effects, and nonlinear mixed effects analysis; and to recommend the best method for analyzing such data.

\section{MATERIALS AND METHODS}

\section{2.a Data}

Hillman et al. (2005) conducted an experiment to study the effectiveness of spray and fans on the thermoregulatory responses of unrestrained cows in a freestall facility. Ten stalls were equipped with ultrasonic transceivers capable of detecting an animal presence and activating the spray when an animal was lying down (Hillman and Lee 2005 and Hillman et al. 2001). Twenty Holstein cows were randomly divided into two groups. One group was assigned to stalls equipped with spray cooling. The animals in this group were sprayed whenever the animal was lying down in the stall. Animals in the other group, which served as a control, were not sprayed while lying in the stall. Generally speaking, the body temperature of an animal rises when it is lying. Spraying helps slow the rise in body temperature; hence, the animal will spend much more time lying. The groups are referred to as control (no spray) group and experimental (spray) group. During the midday experimental trial, visual observations of behavior were made from 13:20 until 15:00 on the first day, (August 19, 2002) and from 11:00 until 15:00 for days 2 to 5 (August 20 to 24, 2002). The following activities were recorded: time of day a cow laid down in the stall, stood up in the stall, stood away from the feed line, and stood at the feed line. Vaginal body temperatures were recorded every 5 minutes with a commercial waterproof temperature logger. An example of changes in body temperature during the observation period at midday is illustrated in Figure 1, where the duration of lying and standing events is labeled. In this example, cow \#9303 (member of the Control group) was observed on day 2. The durations of the individual activities were observed: 17 min standing under feed line, 77 min lying in stall without spray cooling and 64 min standing in feed line. The duration of the final lying activity was not determined because the cow was still lying at the end of observation period.

This study will focus on body temperature for the lying events for day 2. Totally, there are forty-three lying events for day 2 (Figure 2). Twenty-two of the events belong to the control (no spray) group and the rest (21) belong to the experimental (spray).

\section{2.b Model Selection}

A typical lying curve is shown in Figure 3. We model the temperature change in two segments (recovery and challenge): the decreasing segment (recovery or heat loss) which is dominated by the effect of the previous standing activity and the increasing segment (challenge or heat gain) which is dominated by the effect of current lying activity. 
First, we model the curve using the following six-parameter model (Eq. 1), which is a combination of exponential decay and logistic growth:

$$
\mathrm{Y}=\boldsymbol{b} \mathrm{e}^{-\kappa_{\mathrm{e}} \mathrm{X}}+\delta+\frac{\alpha}{1+\mathrm{e}^{-\kappa_{l}\left(\mathrm{X}-\left(\tau+\mathrm{X}_{\min }\right)\right)}}+\varepsilon \quad \varepsilon \sim \mathrm{N}\left(0, \sigma^{2}\right)
$$

where $\mathrm{Y}$ is the body temperature $\left({ }^{\circ} \mathrm{C}\right)$, and $\mathrm{X}$ is the time (minutes). In the exponential decay segment: $\mathrm{b}$ is the difference between the initial temperature, $\mathrm{Y}_{0}$, and the lower asymptote, $\delta\left({ }^{\circ} \mathrm{C}\right)$, and $\kappa_{\mathrm{e}}$ is the decay rate constant. In the logistic growth segment: $\delta$ is the lower asymptote $\left({ }^{\circ} \mathrm{C}\right), \alpha$ is the difference between the upper and lower asymptote $\left({ }^{\circ} \mathrm{C}\right), \kappa_{1}$ is the growth rate constant, $\mathrm{X}_{\min }$ (minute) is the time of the minimum body temperature and $\tau$ is the time to inflection point adjusted for $X_{\min }$ (minute); i.e., $\left(\tau+X_{\min }\right)$ is the time it takes for the animal to reach its maximum rate of change in body temperature. Notice that $\mathrm{X}_{\min }$ in the logistic growth term is a scalar not a parameter, essentially we adjust each logistic growth segment of lying events to have a starting time of zero.

In addition to the six-parameter exponential-logistic model, we considered four modifications. For modification one (Eq. 2), we adjust the rate of decay, $\kappa_{\mathrm{e}}$ (rate of recovery from previous activity). We replace $\kappa_{\mathrm{e}}$ with $5 /\left(\mathrm{X}_{\min }+0.1\right)$. The numerator was arbitrarily set to 5 because $\exp (-5)$ is very close to 0 and 0.1 was added to $X_{\min }$ to prevent division by 0 . Therefore, when $\mathrm{X}=\mathrm{X}_{\min }$ the effect of previous activity disappears.

\section{Adjust Decay Rate}

$$
Y=b e^{-\frac{5}{X_{\min }+0.1} X}+\delta+\frac{\alpha}{1+e^{-\kappa_{l}\left(X-\left(\tau+X_{\min }\right)\right)}+\varepsilon} \quad \varepsilon \sim N\left(0, \sigma^{2}\right)
$$

For the second modification (Eq. 3), we adjust the $\mathrm{Y}$-axis $(\delta)$ and the rate of decay, $\kappa_{\mathrm{e}}$. In addition to replacing $\kappa_{\mathrm{e}}$ with $5 /\left(\mathrm{X}_{\min }+0.1\right)$, we also use the minimum temperature, $\mathrm{Y}_{\min }$ to approximate lower asymptote $(\delta)$.

\section{Adjust Decay Rate and Minimum Response}

$$
Y=b e^{-\frac{5}{X_{\min }+0.1} X}+Y_{\min }+\frac{\alpha}{1+e^{-\kappa_{1}\left(X-\left(\tau+X_{\min }\right)\right)}}+\varepsilon \quad \varepsilon \sim N\left(0, \sigma^{2}\right)
$$

For the third modification (Eq. 4), we adjust both the decay range, b, and the decay rate, $\kappa_{\mathrm{e}}$. We replace b with $\left(\mathrm{Y}_{0}-\mathrm{Y}_{\min }\right)$ and replace $\kappa_{\mathrm{e}}$ with $5 /\left(\mathrm{X}_{\min }+0.1\right)$.

\section{Adjusted Rate and Range of Exponential}

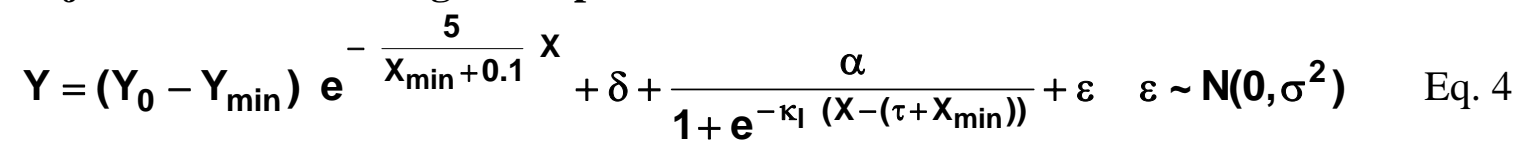

For the last modification (Eq. 5), we adjust all three parameters. We adjust the range and rate of decay (b, $\kappa_{\mathrm{e}}$ ) and use $\mathrm{Y}_{\min }$ to estimate the lower asymptote, $\delta$. For this model, $\alpha$ is the difference between the upper asymptote and $\mathrm{Y}_{\min }$. 
Logistic Model, adjusted for Minimum and Exponential Decay

$$
Y=\left(Y_{0}-Y_{\min }\right) e^{-\frac{5}{X_{\min }+0.1} X}+Y_{\min }+\frac{\alpha}{1+e^{-\kappa_{l}\left(X-\left(\tau+X_{\min }\right)\right)}+\varepsilon \quad \varepsilon \sim N\left(0, \sigma^{2}\right)}
$$

\section{2.c Methods of Comparing Treatment Effects}

Three methods were used to analyze and estimate treatment effects: mixed model analysis of the parameter estimates, nonlinear fixed effects analysis, and nonlinear mixed effects analysis. These methods were evaluated using the logistic model adjusted for the minimum body temperature and exponential decay presented in equation 5.

Due to biological variation in response and management routine within the dairy operation, the forty-three lying events were classified as three categories: all, good, or better. The "all" category included all forty-three lying events without any conditions. The "good" and "better" categories were defined by how well the data fit the model. PROC NLIN in SAS (1999) was used to fit each of the 43 lying events one by one. The nonlinear residual mean square, MSE, and the least squares estimates, SE's, and CI's were obtained for all parameters. If a lying event satisfied the following four conditions: i) convergence; ii) reasonable estimates; iii) no missing SE's for any of the three parameters; and iv) intrinsic curvature less than 0.4 (Bates and Watts, 1980), then the lying event was classified as good; if a lying event satisfied the above four conditions and had parameter effects curvature less than 0.4 (Bates and Watts, 1980), then it was classified as better. Note: If the root mean square parameter effects curvature, PE, is so small that when standardized to the 95\% confidence level, the PE is less than 0.4 (a 21\% deviation of surface from tangent plane), the linear approximation inference regions are considered acceptable (Bates and Watts, 1980). Similar reasoning holds for the standardized intrinsic curvature, IN.

To establish reasonable estimates for each parameter, model fits for all 43 lying events were screened to identify outliers. The steps to find a reasonable range of $\kappa_{1}$ are as follows: first, plot $\kappa_{1}$ vs. number of the lying event and examine lying events producing anomalous model fits. From Figure 4, it is easy to see that most $\kappa_{l}$ fall between -1 and 1 . Since $\kappa_{1}$ is the rate constant for logistic growth (heat gain), it cannot be negative; therefore, the reasonable range of $\kappa_{1}$ is between 0 and 1. Similarly for $\alpha$ and $\tau$, we found that $\alpha$ should be greater than 0 and less than $5^{\circ} \mathrm{C}$ since it is the difference between the upper asymptote and minimum body temperature and $\tau$ should be greater than 0 and less than 120 min since it is the time to the inflection point.

After the lying event was screened and classified, the three methods were used to analyze treatment effects. For the mixed method, each event was fit by the nonlinear fixed effects model, PROC NLIN. Then, each parameter was analyzed using the fixed treatment effects model, PROC MIXED. For the nonlinear fixed effects method, all lying events were fit by PROC NLIN together with two treatment levels (spray and no spray). For the nonlinear mixed effects method, all lying events were fit by Proc NLMIXED. Two 
treatment levels, (spray and no spray) and three random effects were incorporated in the three-parameter logistic model adjusted for minimum and exponential decay (Eq. 6):

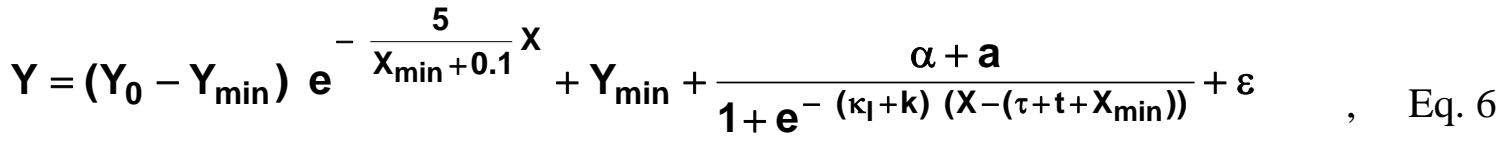

$$
\begin{aligned}
& a \sim N\left(0, \sigma_{a}^{2}\right) \quad k \sim N\left(0, \sigma_{k}^{2}\right) \quad t \sim N\left(0, \sigma_{t}^{2}\right) \quad \varepsilon \sim N\left(0, \sigma^{2}\right)
\end{aligned}
$$

where a, $\mathrm{k}, \mathrm{t}$, and $\varepsilon$ are assumed to be independent.

When evaluating the three methods, we focused on the 19 "better" lying events ( 9 control (no spray) and 10 experimental (spray). In addition, there were noticeable differences in the duration of lying time for different lying events, Figure 3. For practical purposes, we categorized duration (short and long) to assess its effect on the parameter estimates. A lying event with duration less than 75 minutes, which is half of the longest lying time, was considered short; otherwise, the lying event was deemed long. For each treatment comparison method, lying events for the experimental (spray) group were analyzed: ignoring duration (short and long combined) and then separately for each duration (short or long)

\section{2.d Simulation Studies}

Big differences were observed between the three methods of comparing treatment effects. Two possible reasons are: i) large variation among animals; and ii) large differences in the duration of the lying event, $\mathrm{X}_{\max }$. In order to find the best method to use under these conditions, simulation studies were conducted to investigate the effect of the magnitude of variation and differences in duration. For each simulation, the model was reduced to two parameters. The difference between the upper and lower asymptote, $\alpha$, was set to a constant. Three studies were performed. The first two studies focused on the magnitude of variation. The first study was used to compare Type I errors for the three estimation procedures; and the second study was used to compare bias and power for the three estimation procedures. The third study focused on differences in duration (lying time) and was used to compare bias (Box, 1972) and power for the three estimation procedures.

\section{2.d.i Simulations used to study the effect of magnitude of variation in $\tau$ on three estimation procedures}

Consider the following two-parameter logistic model:

$$
\mathrm{Y}=\frac{0.8}{1+\mathrm{e}^{-\kappa(X-\tau)}}+\varepsilon \quad \varepsilon \sim \mathrm{N}(0,0.0005),
$$

where $\kappa$ is a fixed effect and $\tau$ is a random effect distributed normally. The coefficient of variation (CV) of $\tau$ has three levels: $5 \%, 10 \%$, and 20\%. One thousand data sets of size $\mathrm{n}=25$ were generated for each level of the $\mathrm{CV}$ at 5 minute intervals holding duration constant. Hence, the values of $X(0,5,10, \ldots, 120)$ were the same for each simulated data set. There were two treatments, each with ten subjects. For the Type I Error study, we set $\kappa=0.10, E(\tau)=60$, and $\operatorname{var}(\tau)=9$, 36, or 144 depending on the level of the CV for both treatments. For the Power study, we set $\kappa=0.15, E(\tau)=50$, and $\operatorname{var}(\tau)=6.25$, 25, or 
100 for the first treatment; and set $\kappa=0.10, E(\tau)=60$, and $\operatorname{var}(\tau)=9,36$, or 144 in order to keep the same three levels of CV for the second treatment.

\section{2.d.ii Simulation used to study the effect of duration of lying time on the three estimation procedures}

Consider the following three-parameter logistic model:

$$
\mathrm{Y}=\frac{\alpha}{1+\mathrm{e}^{-\mathrm{K}(\mathrm{X}-\tau)}+\varepsilon \quad \varepsilon \sim \mathrm{N}(0,0.0005)}
$$

where $\alpha$ and $\kappa$ are fixed effects, and $\tau$ is a random effect distributed normally. The CV of $\tau$ was set at $10 \%$. For the long duration, we set $\alpha=0.8, \kappa=0.06, E(\tau)=50$, $\operatorname{var}(\tau)=25$, and $X=0,5,10,15, \ldots, 120$; for the short duration, we set $\alpha=0.4, \kappa=0.12, E(\tau)=25$, $\operatorname{var}(\tau)=6.25$, and $X=0,5,10,15, \ldots, 60$. These values were taken from a preliminary analysis of the data. One thousand data sets were generated for each of the 20 duration/subject combinations.

\section{RESULTS AND DISCUSSION}

The results of fitting the six-parameter model and its modifications are shown in Table 1. Problems with the six-parameter model are: i) less than half of the lying events have reasonable estimates and SE's for all six parameters; ii) only 8 lying events have intrinsic curvature less than 0.4 ; iii) none of the lying events has parameter effects curvature, PE, less than 0.4. The possible reason is over-parameterization. Therefore, reducing the number of parameters in the model is a possible solution. All four modifications show improvement compared with the six-parameter model: i) more lying events converged; many more lying events have ii) reasonable estimates, iii) no missing SE's, and iv) intrinsic curvature less than 0.4. For PE less than 0.4, the first two modifications show little or no improvement, while the results from modifications 3 and 4 are much better, particularly modification 4 .

As the final model, we choose the last modification, the three-parameter logistic model adjusted for minimum temperature and range and rate of previous exponential recovery (Eq. 5). The advantages of using this model are: (i) the number of parameters is reduced from 6 to 3; (ii) all 43 lying events converged; (iii) 79\% of the lying events have reasonable estimates.

Among forty-three lying events, thirty-three of them were categorized as good and nineteen were categorized as better (Table 2). For the thirty-three good lying events, only nineteen of them have PE less than 0.4 .

When comparing two treatments using the three estimation methods, we find that the results depend on both the category of lying event and method (Table 3). That is, different categories of lying events give different results and different methods give different results. For the MIXED method, we compare only the results for good and better lying events, since the MIXED method is NOT applicable when using all lying events due to outliers. The estimates for good and better lying events are different for $\alpha$, while the estimates of $\tau$ and $\kappa_{1}$ are similar for both categories, suggesting it is $\alpha$ that is 
inflating the PE curvature. The P-values for good and better lying events are similar for $\alpha$ and $\tau$; but for $\kappa_{l}$, the P-value changes from significant (good lying events) to nonsignificant (better lying events) at 5\% level. For NL FIXED method, the estimates and the P-values from the tests of hypothesis are similar for all three categories. For the NL RANDOM method, the estimates of $\kappa_{1}$ and $\tau$ for the second treatment from all the lying events are very different from the estimates produced by good and better lying events. The P-values for the hypotheses tests are significant for $\alpha$ and $\kappa_{l}$ for all and better lying events, but not for good events.

When we consider only the better lying events and compare the three methods, we find that the results of the hypotheses tests are different. There exist significant differences in $\alpha, \kappa_{1}$, and $\tau$ between two treatments for NL FIXED \& NL RANDOM methods, but not for MIXED method. The parameter estimates are also different: $\alpha$ and $\tau$ from MIXED method are significantly different from NL FIXED and RANDOM methods and $\kappa_{1}$ from NL FIXED procedure is significantly different from MIXED \& NL RANDOM methods.

In order to shed light on the veracity of these results, we turn to the simulation studies. The Type I error for the first simulation study is shown in Table 4. For the MIXED method, the variation in $\tau$ has little effect on Type I error. Type I error is close to 0.05 for all three different levels of CV. For the NL FIXED and NL RANDOM methods, the variations in $\tau$ do have a large effect on Type I error. For the NL FIXED method, none of the Type I errors is less than 0.05 for testing the difference in $\tau$. For the NL RANDOM method, the Type I error is less than 0.05 only at $\mathrm{CV}=5 \%$ for testing differences in both $\kappa$ and $\tau$. Therefore, we conclude that the MIXED method is "best" in the sense it comes closest to obtaining the specified Type I Error.

Power and \% bias for the second simulation study are shown in Table 5 . We found that the variation in $\tau$ has an effect on Power for all 3 procedures. For MIXED method, the power is always greater than 0.95 when testing for differences in $\kappa$. However, when testing for differences in $\tau$, the power is greater than 0.95 when $\mathrm{CV}$ is less than or equal to $10 \%$ and decreases to $50 \%$ when $\mathrm{CV}=20 \%$. For NL FIXED method, the power is greater than 0.95 when $\mathrm{CV}$ is less than or equal to 10 and decreases to $76 \%$ for a $\mathrm{CV}$ of $20 \%$ when testing for differences in $\kappa$. When testing for differences in $\tau$, the power is also greater than 0.95 when $\mathrm{CV}$ is less than or equal to 10 and only decreases slightly (93\%) at CV of 20\%. The NL RANDOM method has good power even when CV increases to $20 \%$ when testing for differences in either $\kappa$ and $\tau$.

We also found that the variation in $\tau$ has different effects on \% bias of the estimators for the three methods. For the MIXED method, the variation in $\tau$ has little effect on bias of the estimator and all bias is less than 1\%. However, for the NL FIXED and NL RANDOM methods, the bias of $\kappa$ increases greatly when the variation in $\tau$ increases and the bias of $\kappa$ is greater than $1 \%$ even at $C V=5 \%$. The same results hold for the bias of the differences $\kappa$ or $\tau$. Therefore, we conclude that the MIXED method has smallest \% bias. 
Another problem with the data is that the duration of lying time is not consistent from lying event to lying event. To study the effect of duration on the parameter estimates, the data was characterized as long or short (see section 2.d.ii). Parameter estimates of better lying events for the experimental spray group by method and duration are shown in Table 6. For the MIXED method, the combined (duration ignored) results are the average of Long and Short effects. The $\alpha$ and $\tau$ estimates from Long are about twice as large as those for Short and $\kappa_{1}$ from Long is about half of the Short estimate. For the NL FIXED and NL RANDOM methods, the combined estimates are dominated by lying events with longer lying time.

The \% biases for the simulation study of the duration of lying time are shown in Table 7. When comparing the results for combined data, we found that all bias is less than or close to $1 \%$ for the MIXED method. Therefore, the bias is acceptable for the MIXED procedure since the combined results are the average of Long and Short durations. For the NL FIXED and NL RANDOM methods, all bias is much larger than $1 \%$ for the combined (duration ignored) estimates. Therefore, the bias is NOT acceptable since combined results are dominated by data with longer duration. The power for all three methods equals 1 .

From the results of the simulation studies, we recommend using the MIXED method to compare the two treatments. The advantages of using this method are: (i) the Type I error is the smallest; (ii) the power is greater than 95\% when the CV of $\tau$ is less than or equal to 10\%; and (iii) the estimates from the combined (duration ignored) results are the average of Long and Short durations.

The recommended analysis consists of, first, estimating the parameters for each lying event using the three-parameter logistic model adjusted for minimum temperature and range and rate of previous exponential recovery (Eq. 5), then, using the MIXED method to detect the difference between the two treatments. The effect of duration and the duration-treatment interaction is also included in the recommended analysis by means of a 2 x2 factorial treatment design.

When using the recommended analysis on the data, we find no significant two-way interaction between treatment and duration for any of the three parameters (Table 8). However, there are significant treatment main effects for $\kappa_{1}$ and $\tau$, but not for $\alpha$; and a significant duration main effect for all three parameters. From the parameter estimates, we find the combination of spray and fan cooling is much more effective than using fan cooling alone. The rate constant of the sprayed cows is lower and it takes longer to reach the maximum rate; (i) the rate constant, $\kappa_{l}$, decreases $0.041 /$ min when spraying $(0.13 \mathrm{vs}$ 0.09); (ii) the time to maximum rate of change in body temp, $\tau$, increases 9 min (25 vs 34). Moreover, the duration effect is significant. When comparing the Long duration with the Short one, we found: (i) the difference between maximum and minimum body temperature, $\alpha$, decreases $0.37^{\circ} \mathrm{C}(0.74$ vs 0.37$)$; (ii) the rate constant $\kappa_{l}$ increases 0.08 $1 / \mathrm{min}$ (0.07 vs 0.15 ); and (iii) $\tau$ decreases $18 \mathrm{~min}$ (38 vs 20). It seems that cows with shorter lying time are more sensitive to increased body temperature. They tolerate less of an increase in body temperature, have a higher rate constant and reach their maximum 
rate more quickly. Notice, if we ignore the effect of duration, the main effect of treatment is only marginally significant for the rate constant, $\kappa_{l}$, and not significant for the other two parameters.

\section{SUMMARY}

This study provides a reasonable nonlinear model to describe dynamics of lying events in Holstein cows. It also provides a tolerable method for estimating and analyzing the resulting parameters, thus, enabling researchers to get better comparisons of the effects of different cooling strategies on the thermoregulatory responses of lying heat stressed cows. For characterizing the lying thermoregulatory responses, the three-parameter logistic model adjusted for minimum response and exponential decay, (heat recovery) is a good choice; while the "mixed" analysis is the preferred method for estimating parameters and comparing cooling treatments. Thus, we recommend: 1) using the nonlinear fixed effects model to estimate the parameters for each lying-down event, 2) screening the results from each lying-down event for convergence, reasonable estimates, missing SE's, intrinsic and parameter effects curvature, and, 3) within each cooling treatment (spray/no spray), classifying duration as long or short. We recommend comparing the treatment groups by analyzing each parameter using the mixed model procedure for a $2 \times 2$ factorial treatment design, with duration as the second factor. From the recommended analysis, we find that the duration has a significant effect on all three parameters and the combination of spray and fan cooling is more effective than using fan cooling alone. 


\section{REFERENCES}

Armstrong, D.V. 1994. Heat stress interaction with shade and cooling. J. Dairy Sci. 77:2044-2050.

Bates, D. M. and D. L. Watts. 1980. "Relative curvature measures of nonlinearity.” J. R. Statist. Soc. Ser. B. 42:1-25.

Box, M. J. 1972. “ Bias in nonlinear estimation.” J. R. Statist. Soc. Ser. B. 33:171-201.

Bray, D.R., R.A. Bucklin, L. Carlos, and V. Cavalho. 2003. Environmental temperatures in a tunnel ventilated barn and in an air conditioned barn in Florida. In Fifth International Dairy Housing Proceedings, 235-242. Fort Worth, Texas, 29-31 January, St. Joseph, Mich.: ASAE.

Brouk, M.J., J.F. Smith, and J.P. Harner, III. 2003. Effect of sprinkling frequency and airflow on respiration rate, body surface temperature and body temperature of heat stressed dairy cattle. In Fifth International Dairy Housing Proceedings, 263-268. Fort Worth, Texas, 29-31 January, St. Joseph, Mich.: ASAE.

Bucklin, R.A., L.W. Turner, D.K. Beede, D.R. Bray, and R.W. Hemken. 1991. Methods to relieve heat stress for dairy cows in hot, humid climates. Applied Engineering in Agriculture 7(2):241-247.

Frazzi, E., L. Calamari, F. Calegari and L. Stefanini. 2000. Behavior of dairy cows in response to different barn cooling systems. Transactions of the ASAE 43(2):387-394.

Friend, T.H. and C.E. Polan. 1974. Social rank, feeding behavior, and freestall utilization by diary cattle. J. Dairy Sci. 57(10):1214-1220.

Haley, D.B., A.M. de Passillé, and J. Rushen. 2001. Assessing cow comfort: effects of two floor types and two tie stall designs on the behaviour of lactating dairy cows. Appl. Anim. Behav. Sci. 71:105-117.

Hayasaka, K. and N. Yamagishi. 1990. Behavioral responses of lactating Holstein cows to rising indoor air temperature in Hokkaido. Jpn. J. Zootech. Sci., 61(8):690-694.

Hillman, P. E., C. N. Lee, and S. T. Willard. 2005. Thermoregulatory responses associated with lying and standing in heat-stressed dairy cows. Trans. ASAE 48(2):795801.

Hillman, P.E., K.G. Gebremedhin, A. Parkhurst, J. Fuquay, and S. Willard. 2001. Evaporative and convective cooling of cows in a hot humid environment. In Livestock Environment VI 
Igono, M.O., H.D. Johnson, B.J. Steevens, G.F. Krause, and M.D. Shanklin. 1987. Physiological, productive, and economic benefits of shade, spray, and fan system versus shade for Holstein cows during summer heat. J. Dairy Sci. 70:1069-1079.

Lin, J.C., B.R. Moss, J.L. Koon, C.A. Flood, R.C. Smith III, K.A. Cummins, and D.A. Coleman. 1998. Comparison of various fan, sprinkler, and mister systems in reducing heat stress in dairy cows. Applied Engineering in Agriculture 14(2):177-182.

Meyer, M.J., J.F. Smith, J.P. Harner, J.E. Shirley, E.C. Titgemeyer, and M.J. Brouk. 2002. Performance of lactating dairy cattle in three different cooling systems. Applied Engineering in Agriculture 18(3):341-345.

Overton, M.W., W.M. Sischo, G.D. Temple, and D.A. Moore. 2002. Using time-lapse video photography to assess dairy cattle lying behavior in a free-stall barn. J. Dairy Sci. 85:2407-2413.

Perera, K.S., F.C. Gwazdauskas, R.E. Pearson, and T.B. Brumback, Jr. 1986. Effect of season and stage of lactation on performance of Holsteins. J. Dairy Sci. 69:228-236.

SAS. 1999. SAS/STAT User’ s Guide. Version 8. SAS Institute Inc., Cary, NC.

Spain, James N. and Don Spiers. 1998. Effect of fan cooling on thermoregulatory responses of lactating diary cattle to moderate heat stress. In Proc. Fourth International Dairy Housing Conference, 232-238. St. Louis, Missouri., 28-30 January, St. Joseph, Mich.: ASAE.

Strickland, J.T., R.A. Bucklin, R.A. Nordstedt, D.K. Beede, and D.R. Bray. 1989. Sprinkler and fan cooling system for dairy cows in hot, humid environments. Applied Engineering in Agriculture 5(2):231-236.

Shultz, T.A. 1984. Weather and shade effects on cow corral activities. J. Dairy Sci., 67:868-873.

Turner, L.W., J.P. Chastian, R.W. Hemken, R.S. Gates, and W.L. Crist. 1992. Reducing heat stress in dairy cows through sprinkler and fan cooling. Applied Engineering in Agriculture 8(2):251-256. 
Figure 1. Example of the Activities and Vaginal Body Temperature (C) of Cow during the Midday Observation Period. In this example, cow9309 (a member of the control group) was observed illustrating the rise in temperature during lying activity and fall in temperature during the standing activity.

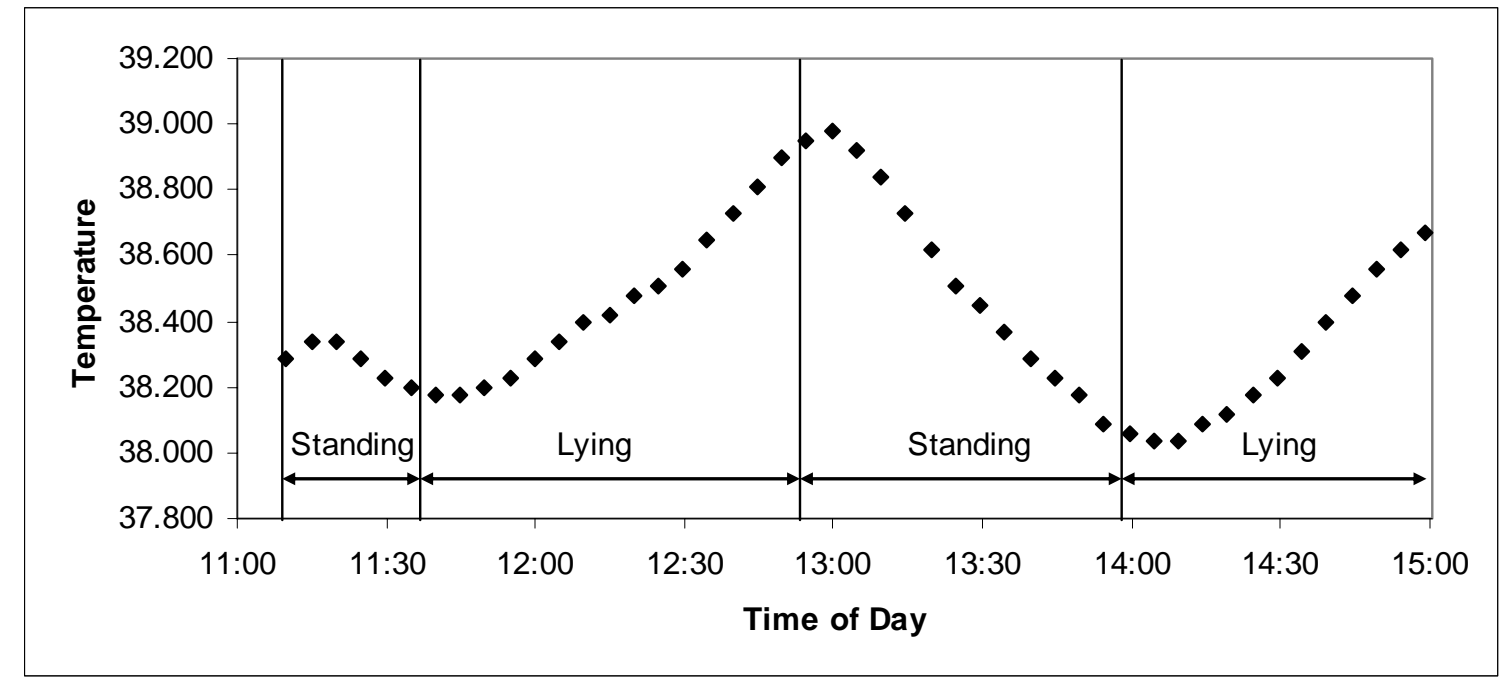

Figure 2. Forty-three Lying Events (22 Control-No Spray, 21 Spray) of Body Temperature (C) versus Time (min) Showing the Variation in the Duration of Lying Events

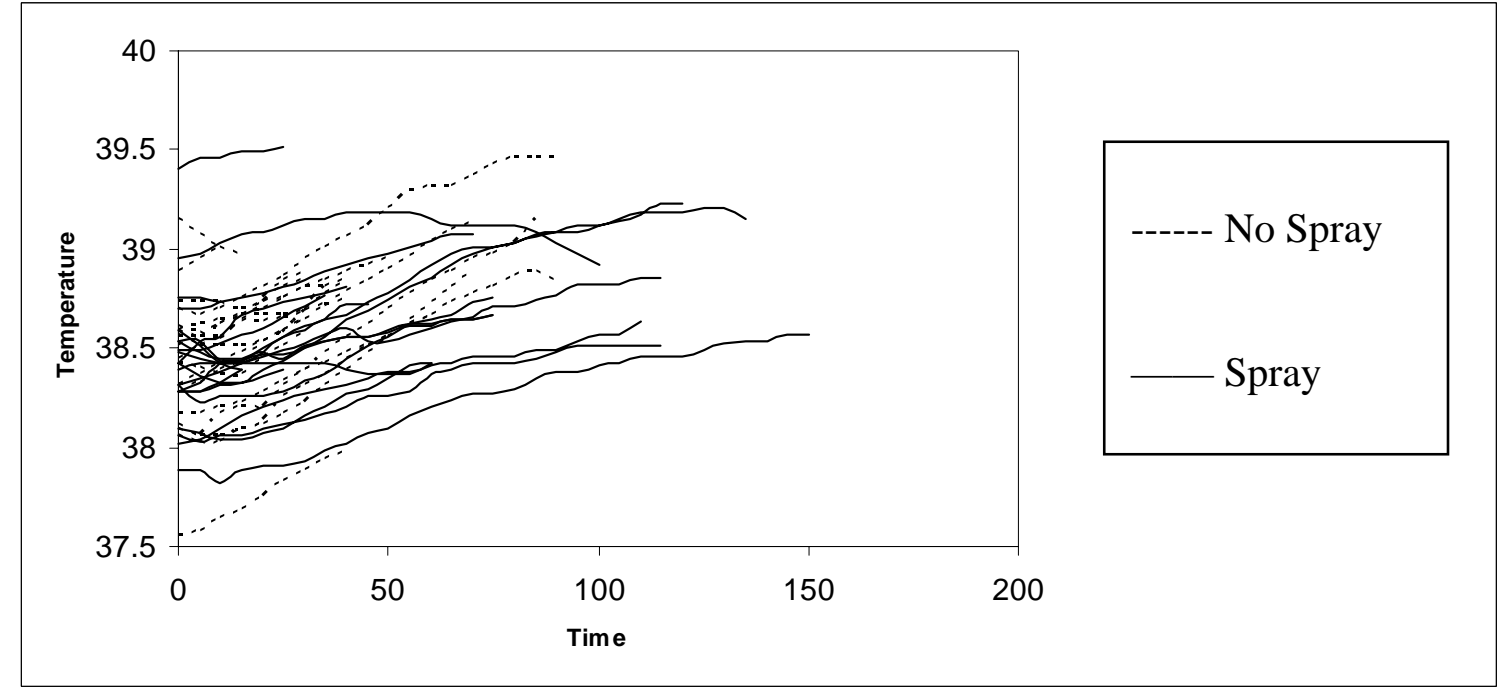


Figure 3. A Typical Lying Curve. This example illustrates two segments for temperature change: the decreasing segment which is dominated by the effect of the previous standing activity and the increasing segment which is dominated by the effect of lying activity. (Cow\#307 Time=14:03-15:07 Day2)

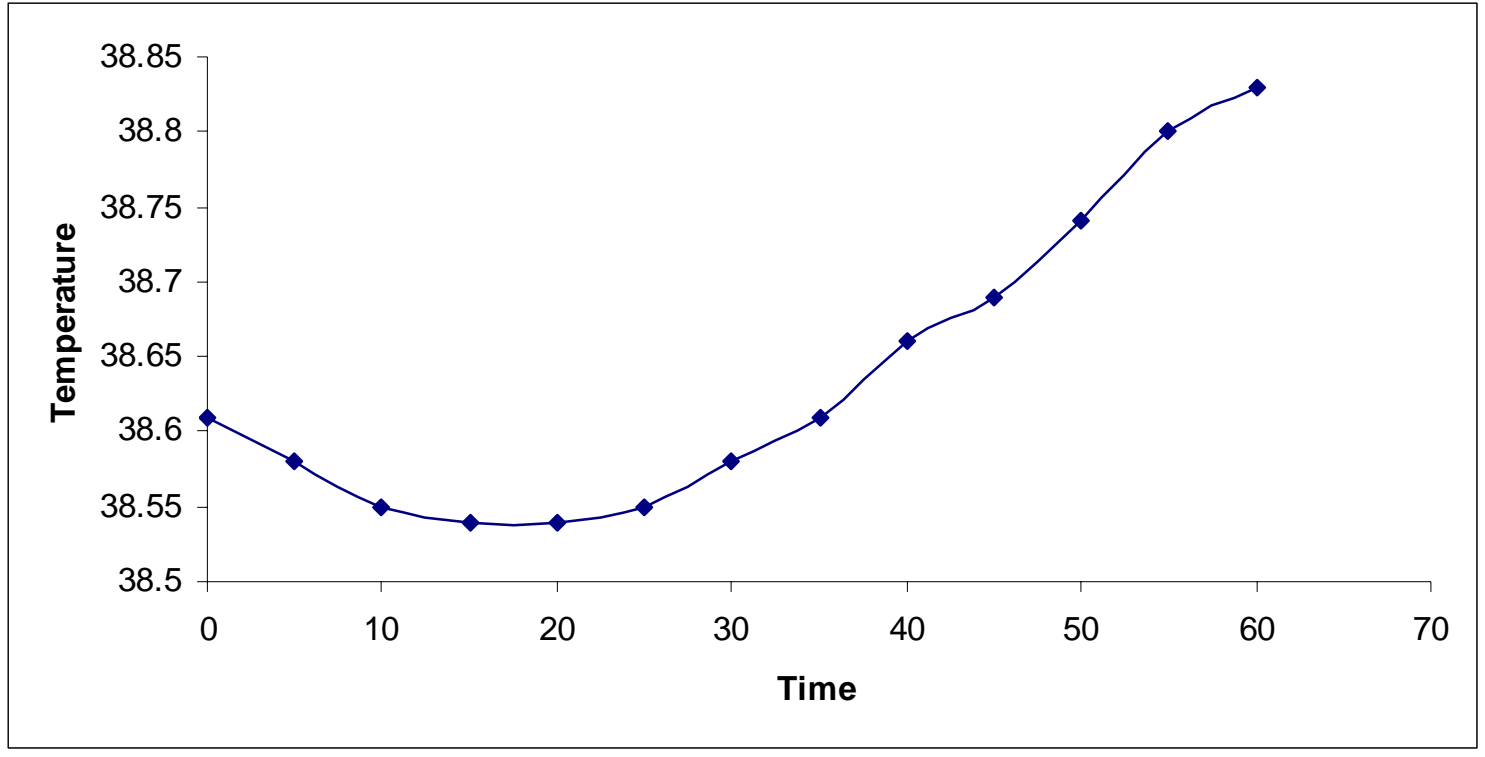

Figure 4. Identification of Unreasonable Estimates: Thermal Constant Estimates, $\kappa_{\mathfrak{l}}$, versus Number of the Lying Event*

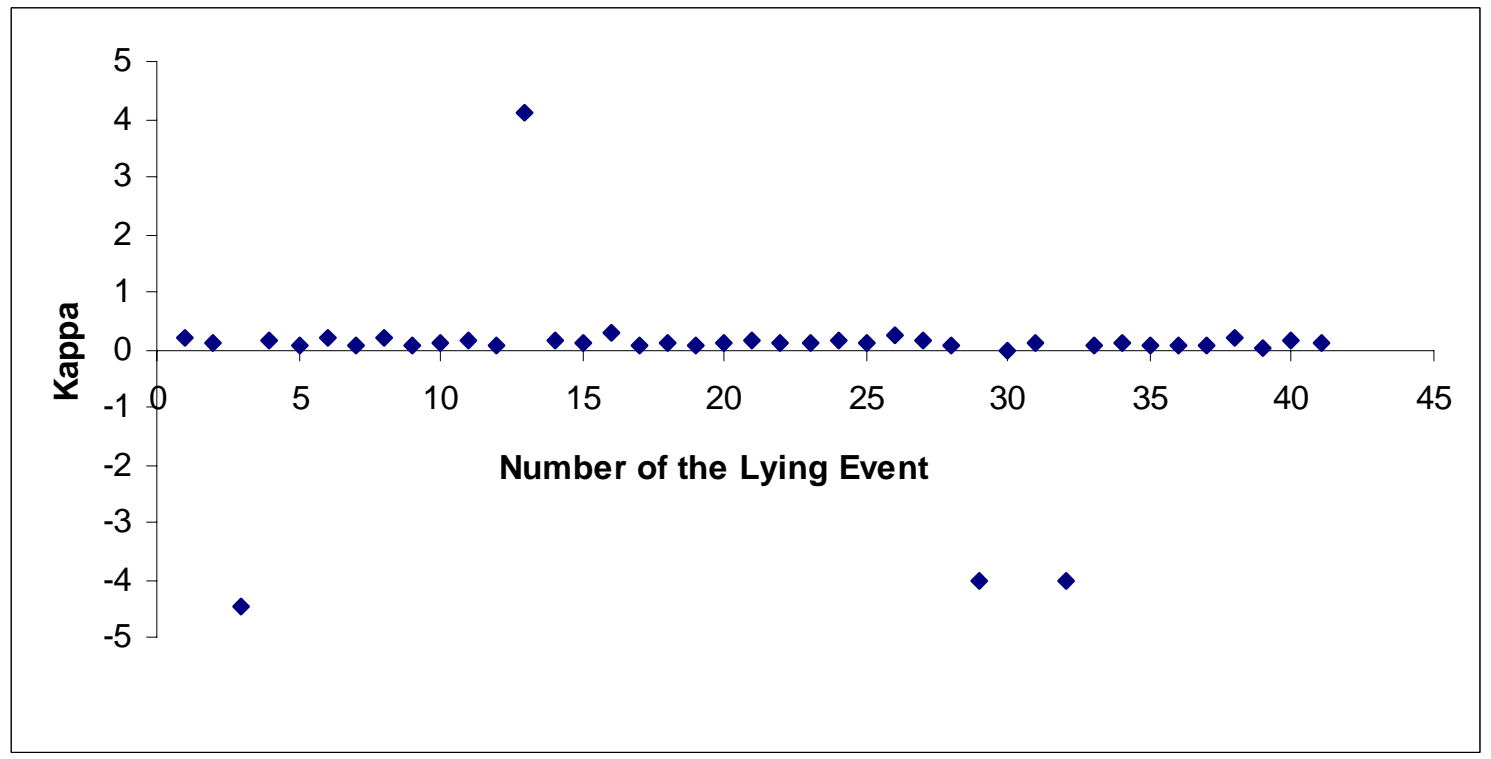

*Note: Two lying events ( $\# 42, \kappa_{1}=1.52 \times 10^{13}$ and $\# 43, \kappa_{1}=-1.97 \times 10^{6}$ ) are not shown in the plot. Further inspection shows all lying events producing anomalous results do not have enough observations to get reasonable estimates for all parameters in the model. 
Table 1. Compare Six-Parameter Model and its Modifications by Number of Lying Events Satisfying Criteria (Total=43)

\begin{tabular}{|c|c|c|c|c|c|}
\hline \multirow{2}{*}{ CRITERIA } & & \multicolumn{4}{|c|}{ MODIFICATION } \\
\cline { 2 - 6 } & $\begin{array}{c}6- \\
\text { Parameter } \\
\text { Model }\end{array}$ & $\begin{array}{c}\text { Adjust } \\
\text { Decay Rate }\end{array}$ & $\begin{array}{c}\text { Adjust Y \& } \\
\text { Decay Rate }\end{array}$ & $\begin{array}{c}\text { Adjust } \\
\text { Decay } \\
\text { Range \& } \\
\text { Rate }\end{array}$ & $\begin{array}{c}\text { Adjust All } \\
3\end{array}$ \\
\hline $\begin{array}{c}{ }^{1} \text { Converged } \\
\begin{array}{c}{ }^{2} \text { Reasonable } \\
\text { Estimates } \\
0<\alpha<5\end{array} \\
0<\kappa l<1\end{array}$ & 33 & 39 & 39 & 41 & 43 \\
$0<\tau<120$ & 14 & 27 & 26 & 32 & 34 \\
\hline${ }^{3}$ No missing SE's & 17 & 28 & 30 & 34 & 34 \\
\hline${ }^{4}$ Intrinsic $<0.4$ & 8 & 39 & 39 & 41 & 38 \\
\hline${ }^{5}$ PE $<0.4$ & 0 & 0 & 1 & 17 & 22 \\
\hline
\end{tabular}

6-Parameter Model: $\mathbf{Y}=\mathbf{b} \mathbf{e}^{-\kappa_{\mathrm{e}} \mathrm{X}}+\delta+\frac{\alpha}{1+\mathrm{e}^{-\kappa_{\mathrm{l}}\left(\mathrm{X}-\left(\tau+\mathrm{X}_{\min }\right)\right)}}+\varepsilon \quad \varepsilon \sim \mathrm{N}\left(0, \sigma^{2}\right)$

1: Adjust Decay Rate: $\mathbf{Y}=\mathbf{b} \mathrm{e}^{-\frac{5}{\mathrm{X}_{\min }+\mathbf{0 . 1}} \mathrm{X}}+\delta+\frac{\alpha}{1+\mathrm{e}^{-\mathrm{K}_{\mathrm{l}}\left(\mathrm{X}-\left(\tau+\mathrm{X}_{\min }\right)\right)}}+\varepsilon \quad \varepsilon \sim \mathrm{N}\left(\mathbf{0}, \sigma^{2}\right)$

2: Adjust $Y$ \& Decay Rate: $Y=b e^{-\frac{5}{X_{\min }+0.1} X}+Y_{\min }+\frac{\alpha}{1+e^{-k_{l}\left(X-\left(\tau+X_{\min }\right)\right)}}+\varepsilon \quad \varepsilon \sim N\left(0, \sigma^{2}\right)$

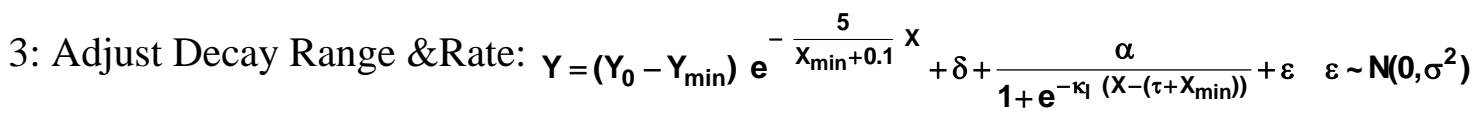

4: Adjust All: $\mathrm{Y}=\left(\mathrm{Y}_{0}-\mathrm{Y}_{\min }\right) \mathrm{e}^{-\frac{5}{\mathrm{X}_{\min }+0.1} \mathrm{X}}+\mathrm{Y}_{\min }+\frac{\alpha}{1+\mathrm{e}^{-\mathrm{\kappa}_{l}\left(\mathrm{X}-\left(\tau+\mathrm{X}_{\min }\right)\right)}}+\varepsilon \quad \varepsilon \sim \mathrm{N}\left(0, \sigma^{2}\right)$

${ }^{1}$ model converged for lying event; ${ }^{2}$ reasonable estimates for all three parameters of model; ${ }^{3}$ no missing SE's for any of the three parameters; ${ }^{4}$ intrinsic curvature less than 0.4 ; and ${ }^{5}$ parameter effects curvature less than 0.4 . 
Table 2. Comparison of Results ${ }^{\dagger}$ for 3 Categories of Lying Events by Number of Lying Events Satisfying Criteria

\begin{tabular}{|c|c|c|c|}
\hline CRITERIA & ALL $^{*}$ & GOOD $^{* *}$ & BETTER $^{* * *}$ \\
\hline \# of Lying Events & 43 & 33 & 19 \\
\hline${ }^{1}$ Converged & 43 & 33 & 19 \\
\hline $\begin{array}{c}{ }^{2} \text { Reasonable } \\
\text { Estimates } \\
0<\alpha<5\end{array}$ & 34 & & 19 \\
$0<\kappa l<1$ & 33 & \\
$0<\tau<120$ & & & 19 \\
\hline${ }^{3}$ No missing SE's & 34 & 33 & 19 \\
\hline${ }^{4}$ Intrinsic $<0.4$ & 38 & 33 & 19 \\
\hline${ }^{5}$ PE $<0.4$ & 22 & 19 & \\
\hline
\end{tabular}

${ }^{\dagger}$ Using adjusted 3-parmeter logistic model

$\mathrm{Y}=\left(\mathrm{Y}_{0}-\mathrm{Y}_{\min }\right) \mathrm{e}^{-\frac{5}{\mathrm{X}_{\min }+0.1} \mathrm{X}}+\mathrm{Y}_{\min }+\frac{\alpha}{1+\mathrm{e}^{-\mathrm{K}_{1}\left(X-\left(\tau+X_{\min }\right)\right)}}+\varepsilon \quad \varepsilon \sim \mathrm{N}\left(0, \sigma^{2}\right)$

${ }^{1}$ model converged for lying event; ${ }^{2}$ reasonable estimates for all three parameters of model; ${ }^{3}$ no missing SE's for any of the three parameters; ${ }^{4}$ intrinsic curvature less than 0.4 ; and ${ }^{5}$ parameter effects curvature less than 0.4 .

*All 43 lying events are classified as all without any restriction

** A lying event is classified as good if it satisfies the first four criteria

${ }^{* * *}$ A lying event is classified as better if it satisfies all five criteria 
Table 3. Compare Parameter Estimates ${ }^{\dagger}$ for Two Treatments Using Three Estimation Methods on Three Categories of Lying Events

\begin{tabular}{|c|c|c|c|c|c|c|c|c|}
\hline \multirow{3}{*}{$\begin{array}{c}\text { Estimation } \\
\text { Method }\end{array}$} & \multirow{3}{*}{$\begin{array}{c}\text { PARM } \\
\text { Estimate }\end{array}$} & \multirow{3}{*}{$\mathrm{TRT}^{*}$} & \multicolumn{6}{|c|}{ Category of Lying Event } \\
\hline & & & \multicolumn{2}{|c|}{$\mathrm{All}^{* *}$} & \multicolumn{2}{|c|}{ Good $^{* * *}$} & \multicolumn{2}{|c|}{ Better $^{* * * *}$} \\
\hline & & & Estimate & $\mathrm{P}$-value & Estimate & P-value & Estimate & P-value \\
\hline \multirow{6}{*}{${ }^{1}$ MIXED } & \multirow{2}{*}{$\alpha$} & 1 & .44 & \multirow{2}{*}{.31} & .53 & \multirow{2}{*}{.53} & .61 & \multirow{2}{*}{.50} \\
\hline & & 2 & 7115438 & & .47 & & .53 & \\
\hline & \multirow{2}{*}{$\kappa_{l}$} & 1 & $6.89 \mathrm{E} 11$ & \multirow{2}{*}{.33} & .13 & \multirow{2}{*}{.03} & .13 & \multirow{2}{*}{.055} \\
\hline & & 2 & -93588 & & .09 & & .09 & \\
\hline & \multirow{2}{*}{$\tau$} & 1 & $-8.94 \mathrm{E} 12$ & \multirow{2}{*}{.31} & 25.03 & \multirow{2}{*}{.13} & 25.51 & \multirow{2}{*}{.12} \\
\hline & & 2 & $1.15 \mathrm{E} 16$ & & 32.31 & & 34.22 & \\
\hline \multirow{6}{*}{${ }^{2} \mathrm{NL}$ FIXED } & \multirow[b]{2}{*}{$\alpha$} & 1 & .90 & \multirow{2}{*}{$<.05$} & .90 & \multirow{2}{*}{$<.05$} & .89 & \multirow{2}{*}{$<.05$} \\
\hline & & 2 & .70 & & .69 & & .71 & \\
\hline & \multirow{2}{*}{$\kappa_{l}$} & 1 & .07 & \multirow{2}{*}{$<.05$} & .07 & \multirow{2}{*}{$<.05$} & .08 & \multirow{2}{*}{$<.05$} \\
\hline & & 2 & .05 & & .05 & & .05 & \\
\hline & \multirow{2}{*}{$\tau$} & 1 & 39.13 & \multirow{2}{*}{$<.05$} & 39.27 & \multirow{2}{*}{$<.05$} & 36.28 & \multirow{2}{*}{$<.05$} \\
\hline & & 2 & 49.09 & & 48.56 & & 47.03 & \\
\hline \multirow{6}{*}{ NL RANDOM } & & 1 & .83 & 01 & .76 & 12 & .83 & 05 \\
\hline & $\alpha$ & 2 & .60 & .01 & .65 & .13 & .69 & כ. \\
\hline & & 1 & .12 & $<01$ & .08 & 07 & .13 & $<01$ \\
\hline & $\mathrm{K}_{\mathrm{l}}$ & 2 & .03 & .01 & .08 & 197 & .08 & $<.0$ \\
\hline & & 1 & 38.07 & $<01$ & 35.15 & $<01$ & 36.12 & 601 \\
\hline & $\tau$ & 2 & 17.59 & $<.01$ & 50.74 & $<.01$ & 53.16 & $<.01$ \\
\hline
\end{tabular}

${ }^{\dagger}$ Using adjusted 3-parmeter logistic model

$\mathrm{Y}=\left(\mathrm{Y}_{0}-\mathrm{Y}_{\min }\right) \mathrm{e}^{-\frac{5}{\mathrm{X}_{\min }+0.1} \mathrm{X}}+\mathrm{Y}_{\min }+\frac{\alpha}{1+\mathrm{e}^{-\mathrm{K}_{1}\left(\mathrm{X}-\left(\tau+\mathrm{X}_{\min }\right)\right)}+\varepsilon \quad \varepsilon \sim \mathrm{N}\left(0, \sigma^{2}\right)}$

* 1 represents control (no spray) treatment and 2 represents the experimental treatment (with spray).

${ }_{* * *}^{*}$ All 43 lying events are classified as all without any restriction

** A lying event is classified as good if it satisfies the following four conditions: (i) convergence; (ii) reasonable estimates; (iii) no missing SE's for any of the three parameters; and (iv) intrinsic curvature less than 0.4.

${ }^{* * *}$ A lying event is classified as better if it satisfies all the four conditions of good lying events and has parameter effect curvature less than 0.4.

${ }^{1}$ Parameters estimated from nonlinear fixed effects model (proc nlin) are analyzed for treatment effects by linear fixed effects model (proc mixed)

${ }^{2}$ Nonlinear fixed effects model (proc nlin)

${ }^{3}$ Nonlinear mixed effects model with cows as random effect (proc nlmixed) 
Table 4. Simulation Study I: P-values for Type I Error for Treatment Differences ${ }^{\dagger}$ Using Three Estimation Methods

\begin{tabular}{|c|c|c|c|c|c|c|c|c|c|c|}
\hline \multirow{2}{*}{\multicolumn{2}{|c|}{$\begin{array}{c}\text { Procedure } \\
\mathrm{CV} \text { of } \tau(\%)\end{array}$}} & \multicolumn{3}{|c|}{ MIXED $^{1}$} & \multicolumn{3}{|c|}{ NL FIXED $^{2}$} & \multicolumn{3}{|c|}{ NL RANDOM $^{3}$} \\
\hline & & 5 & 10 & 20 & 5 & 10 & 20 & 5 & 10 & 20 \\
\hline Type I & Diff_ $\kappa$ & .06 & .06 & .04 & $<.01$ & $<.01$ & .04 & .02 & .18 & .60 \\
\hline error & Diff_ $\tau$ & .04 & .04 & .04 & .47 & .55 & .56 & .03 & .42 & .70 \\
\hline
\end{tabular}

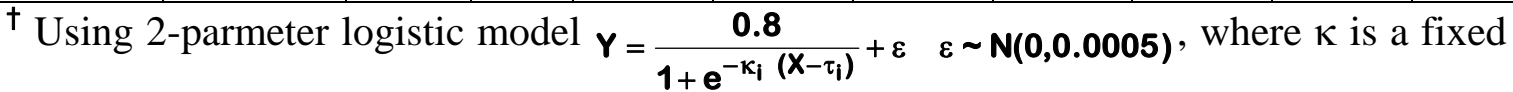
effect and $\tau$ is a random effect distributed normally. The coefficient of variation (CV) of $\tau$ has three levels: 5\%, 10\%, and 20\%. There were two treatments. For both treatments, we set $\kappa=0.10, E(\tau)=60$, and $\operatorname{var}(\tau)=9$, 36, or 144 depending on the level of the $C V$.

${ }^{1}$ Parameters estimated from nonlinear fixed effects model (proc nlin) are analyzed for treatment effects by linear fixed effects model (proc mixed)

${ }^{2}$ Nonlinear fixed effects model (proc nlin)

${ }^{3}$ Nonlinear mixed effects model with cows as random effect (proc nlmixed)

Table 5. Simulation Study II: Power and \% Bias for Treatment Differences ${ }^{\dagger}$ Using Three Estimation Methods

\begin{tabular}{|c|c|c|c|c|c|c|c|c|c|c|}
\hline \multirow{2}{*}{\multicolumn{2}{|c|}{$\begin{array}{c}\text { Procedure } \\
\text { CV of } \tau(\%)\end{array}$}} & \multicolumn{3}{|c|}{ Mixed $^{1}$} & \multicolumn{3}{|c|}{ NL FIXED $^{2}$} & \multicolumn{3}{|c|}{ NL RANDOM $^{3}$} \\
\hline & & 5 & 10 & 20 & 5 & 10 & 20 & 5 & 10 & 20 \\
\hline \multirow{2}{*}{ Power } & Diff_א & $>.99$ & $>.99$ & $>.99$ & $>.99$ & $>.99$ & .76 & $>.99$ & $>.99$ & .97 \\
\hline & Diff_ $\tau$ & $>.99$ & .97 & .50 & $>.99$ & $>.99$ & .93 & $>.99$ & $>.99$ & .92 \\
\hline \multirow{6}{*}{$\%$ Bias } & $\kappa 1$ & .3 & .3 & .3 & 2.3 & 8.3 & 23.6 & 2.4 & 8.7 & 24.3 \\
\hline & $\tau 1$ & $<.1$ & $<.1$ & .1 & $<.1$ & $<.1$ & .1 & $<.1$ & $<.1$ & $<.1$ \\
\hline & $\kappa 2$ & .1 & .1 & .1 & 1.6 & 5.7 & 17.7 & 1.6 & 6.0 & 18.2 \\
\hline & $\tau 2$ & $<.1$ & $<.1$ & $<.1$ & $<.1$ & $<.1$ & $<.1$ & $<.1$ & .1 & .2 \\
\hline & Diff_ $\kappa$ & .6 & .6 & .6 & 3.8 & 13.3 & 35.4 & 4.0 & 14.1 & 36.3 \\
\hline & Diff_ $\tau$ & .1 & .1 & .1 & .1 & .1 & .1 & .2 & .5 & .8 \\
\hline
\end{tabular}

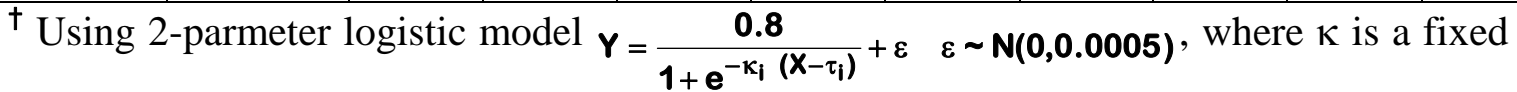

effect and $\tau$ is a random effect distributed normally. The coefficient of variation (CV) of $\tau$ has three levels: $5 \%, 10 \%$, and $20 \%$. There were two treatments. We set $\kappa=0.15$, $E(\tau)=50$, and $\operatorname{var}(\tau)=6.25,25$, or 100 for the first treatment; and set $\kappa=0.10, E(\tau)=60$, and $\operatorname{var}(\tau)=9,36$, or 144 for the second treatment in order to keep the same three levels of CV.

${ }^{1}$ Parameters estimated from nonlinear fixed effects model (proc nlin) are analyzed for treatment effects by linear fixed effects model (proc mixed)

${ }^{2}$ Nonlinear fixed effects model (proc nlin)

${ }^{3}$ Nonlinear mixed effects model with cows as random effect (proc nlmixed) 
Table 6. Parameter Estimates ${ }^{\dagger}$ from Better Lying Events for the Experimental Spray Group by Method and Duration

\begin{tabular}{|c|c|c|c|c|c|c|c|c|c|c|}
\hline \multirow{2}{*}{ Duration } & \multirow{2}{*}{$\begin{array}{c}\text { Number } \\
\text { of } \\
\text { events }\end{array}$} & $\alpha$ & $\kappa_{1}$ & $\tau$ & $\alpha$ & $\kappa_{1}$ & $\tau$ & $\alpha$ & $\kappa_{1}$ & $\tau$ \\
\hline $\begin{array}{c}\text { Long }>75 \\
\text { min }\end{array}$ & 5 & .69 & .06 & 43.8 & .71 & .05 & 45.3 & .72 & .07 & 55.8 \\
\hline $\begin{array}{c}\text { Short } \leq 75 \\
\text { min }\end{array}$ & 5 & .38 & .12 & 24.6 & .48 & .07 & 33.9 & .48 & .11 & 33.4 \\
\hline $\begin{array}{c}\text { Ignored } \\
\text { (Long+Short } \\
\text { Combined) }\end{array}$ & 10 & .53 & .09 & 34.2 & .71 & .05 & 47.0 & .67 & .08 & 53.1 \\
\hline
\end{tabular}

${ }^{\dagger}$ Using adjusted 3-parmeter logistic model

$\mathrm{Y}=\left(\mathrm{Y}_{0}-\mathrm{Y}_{\min }\right) \mathrm{e}^{-\frac{5}{\mathrm{X}_{\min }+0.1} \mathrm{X}}+\mathrm{Y}_{\min }+\frac{\alpha}{1+\mathrm{e}^{-\mathrm{K}_{1}\left(X-\left(\tau+X_{\min }\right)\right)}}+\varepsilon \quad \varepsilon \sim \mathrm{N}\left(0, \sigma^{2}\right)$

${ }^{1}$ Parameters estimated from nonlinear fixed effects model (proc nlin) are analyzed for treatment effects by linear fixed effects model (proc mixed)

${ }^{2}$ Nonlinear fixed effects model (proc nlin)

${ }^{3}$ Nonlinear mixed effects model with cows as random effect (proc nlmixed)

Table 7. Simulation Study III: \% Bias for Parameter Estimates ${ }^{\dagger}$ and Two Duration Classes Using Three Estimation Methods

\begin{tabular}{|c|c|c|c|c|c|c|c|c|c|}
\hline \multirow{2}{*}{ Duration } & \multicolumn{3}{|c|}{ MIXED $^{1}$} & \multicolumn{3}{c|}{ NL FIXED $^{2}$} & \multicolumn{3}{c|}{ NL RANDOM $^{3}$} \\
\cline { 2 - 10 } & $\alpha$ & $\kappa$ & $\tau$ & $\alpha$ & $\kappa$ & $\tau$ & $\alpha$ & $\kappa$ & $\tau$ \\
\hline Long $>75 \mathrm{~min}$ & 0.06 & 0.14 & 0.03 & 0.08 & 1.70 & 0.05 & 0.08 & 1.75 & 0.09 \\
\hline Short $\leq 75 \mathrm{~min}$ & 0.33 & 1.47 & 0.30 & 0.08 & 1.53 & 0.05 & 0.06 & 1.52 & 0.01 \\
\hline $\begin{array}{c}\text { Ignored } \\
\text { (Long+Short } \\
\text { Combined) }\end{array}$ & 0.15 & 1.02 & 0.12 & 36.00 & 41.00 & 36.00 & 35.00 & 41.00 & 36.00 \\
\hline
\end{tabular}

${ }^{\dagger}$ Using adjusted 3-parmeter logistic model

$\mathrm{Y}=\left(\mathrm{Y}_{0}-\mathrm{Y}_{\min }\right) \mathrm{e}^{-\frac{5}{\mathrm{X}_{\min }+0.1} \mathrm{X}}+\mathrm{Y}_{\min }+\frac{\alpha}{1+\mathrm{e}^{-\mathrm{K}_{1}\left(\mathrm{X}-\left(\tau+\mathrm{X}_{\min }\right)\right)}}+\varepsilon \quad \varepsilon \sim \mathrm{N}\left(0, \sigma^{2}\right)$, where $\alpha$ and $\kappa$ are fixed

effects, and $\tau$ is a random effect distributed normally. The CV of $\tau$ is set at $10 \%$. For the long duration, we set $\alpha=.8, \kappa=.06, \mathrm{E}(\tau)=50, \operatorname{var}(\tau)=25$; for the short duration, we set $\alpha=.4$, $\kappa=.12, \mathrm{E}(\tau)=25, \operatorname{var}(\tau)=6.25$.

${ }^{1}$ Parameters estimated from nonlinear fixed effects model (proc nlin) are analyzed for treatment effects by linear fixed effects model (proc mixed)

${ }^{2}$ Nonlinear fixed effects model (proc nlin)

${ }^{3}$ Nonlinear mixed effects model with cows as random effect (proc nlmixed) 
Table 8. P-values for Recommended Analysis ${ }^{\dagger}$ of treatment effects (spray, no spray) with and without Duration Effect

\begin{tabular}{|c|c|c|c|}
\hline MIXED $^{\text {t† }}$ & Parameter & Effect & $\mathrm{P}$-value \\
\hline \multirow{3}{*}{$\begin{array}{c}\text { Incorporate the Effect of } \\
\text { Duration }^{t+t} \text { in the } \\
\text { Analysis }\end{array}$} & $\alpha$ & $\begin{array}{c}\text { Trt } \\
\text { Duration } \\
\text { Trt*Duration }\end{array}$ & $\begin{array}{l}0.4526 \\
<.0001 \\
0.3642\end{array}$ \\
\hline & $\kappa_{1}$ & $\begin{array}{c}\text { Trt } \\
\text { Duration } \\
\text { Trt*Duration } \\
\end{array}$ & $\begin{array}{l}0.0003 \\
<.0001 \\
0.1146 \\
\end{array}$ \\
\hline & $\tau$ & $\begin{array}{c}\text { Trt } \\
\text { Duration } \\
\text { Trt*Duration }\end{array}$ & $\begin{array}{l}0.0110 \\
<.0001 \\
0.6810 \\
\end{array}$ \\
\hline \multirow{3}{*}{$\begin{array}{l}\text { Ignore the Effect of } \\
\text { Duration in the Analysis }\end{array}$} & $\alpha$ & Trt & 0.5001 \\
\hline & $\kappa_{1}$ & Trt & 0.0551 \\
\hline & $\tau$ & Trt & 0.1210 \\
\hline
\end{tabular}

${ }^{\dagger}$ Using adjusted 3-parmeter logistic model

$\mathrm{Y}=\left(\mathrm{Y}_{0}-\mathrm{Y}_{\min }\right) \mathrm{e}^{-\frac{5}{\mathrm{X}_{\min }+0.1} \mathrm{X}}+\mathrm{Y}_{\min }+\frac{\alpha}{1+\mathrm{e}^{-\mathrm{k}_{1}\left(\mathrm{X}-\left(\tau+X_{\min }\right)\right)}+\varepsilon} \quad \varepsilon \sim \mathrm{N}\left(0, \sigma^{2}\right)$. Parameters estimated

from nonlinear fixed effects model (proc nlin) were analyzed for treatment effects by linear fixed effects model (proc mixed)

${ }^{{ }^{+\dagger}}$ Parameters estimated from nonlinear fixed effects model (proc nlin) were analyzed for treatment and duration effects by linear fixed effects model (proc mixed). The MIXED procedure was also rerun ignoring the duration effect.

ttt Two levels: Long $>75$ min and Short $\leq 75$ min 